\title{
Solvothermal Synthesis of ZnO-Nitrogen Doped Graphene Composite and its Application as Catalyst for Photodegradation of Organic Dye Methylene Blue
}

\author{
Rajinder Singh, Manesh Kumar, Heena Khajuria, Jigmet Ladol, \\ and Haq Nawaz Sheikh ${ }^{\star}$
}

Department of Chemistry, University of Jammu, Jammu Tawi, 180006 India.

*Corresponding author: E-mail: hnsheikh@rediffmail.com

Received: $10-11-2017$

\begin{abstract}
A facile one step solvothermal method is designed for the synthesis of visible light-sensitive $\mathrm{ZnO}$-nitrogen doped graphene (ZNG) nano photocatalysts using ethylene glycol as a solvent as well as an agent to prevent aggregation of graphene layers. The deposition of $\mathrm{ZnO}$ nanoparticles onto the NG layers was confirmed by high resolution transmission electron microscope (HR-TEM), scanning electron microscope (SEM), powder X-ray diffraction (XRD), and Fourier transform infrared spectroscopy (FTIR). UV-Vis spectroscopy (UV-Vis) was used to study the enhanced photocatalytic activity, which shows the red-shift of the band-edge as compared to $\mathrm{ZnO}$ nano particles. The enhancement in photocatalytic activity is possibly due to the synergistic effect of improved adsorptivity of dyes, enhanced visible light absorption and effective charge separation.
\end{abstract}

Keywords: $\mathrm{ZnO}$; photocatalysis; methylene blue; nitrogen doped graphene

\section{Introduction}

The visible light degradation of organic pollutants have attracted the attention of the scientific community worldwide due to the various reasons such as better efficiency, easy to operate and non toxic byproducts. ${ }^{1-6}$ The process of photocatalysis takes place by the absorption of light by the photocatalysts such as $\mathrm{ZnO}$ and $\mathrm{TiO}_{2}$ and thereby promoting the electrons from valence band to the conduction band and forming the electron and hole pairs in the structure. ${ }^{7-9}$ The produced electron-hole pairs can move and start the various redox reactions involving water and oxygen and thus cause the degradation of organic molecules. However, the recombination of electrons and holes can lower the performance of photocatalyst $\mathrm{ZnO}{ }^{10}$ In order to make the catalyst more effective, the recombination of electron and hole must be hindered. Various experiments have been conducted to prevent the recombination of electron and hole by combining the photocatalyst with the other materials such as non reactive metals ${ }^{11,14}$ and semiconductors. ${ }^{15,16}$ In addition, it has been found that deposition of semiconductor photocatalysts on a co-adsorbent surface such as mesoporous materials, zeolites, alumina, silica or carbon based materials may en- hance the photocatalytic activity of photocatalysts. ${ }^{17-21}$ Among the various materials, carbon based materials are of great importance due to their excellent electronic properties, adsorption capacity and unique structure. The carbon based materials include activated carbon, graphene and carbon nanotubes. ${ }^{21-27}$ Graphene is a two-dimensional monolayer network of conjugated carbon atoms having $\mathrm{sp}^{2}$-hybridization between the atoms. ${ }^{28-32}$ Graphene has many advantages as compared to the carbon nanotubes (CNTs) such as high surface area and excellent adsorption on the surface of adsorbent. Graphene possesses the excellent electrical, thermal and mechanical properties by virtue of which it is used in the diverse areas and also as electrode materials for electrochemical capacitor. ${ }^{31-34}$ However, despite all these facts graphene has to undergo some structural transformation to be used for many other applications. ${ }^{35}$ The doping of graphene with the heteroatom (i.e, $\mathrm{N}$-atom) can enhance the electron mobility and causes the larger capacitance. All these properties are attributed to the atomic size and strong valence bonds of nitrogen atoms. ${ }^{36}$ In the recent years, nitrogen doped graphene (NG) has received much importance ${ }^{37,38}$ Thus, it is favored to synthesize the $\mathrm{N}$-doped graphene based nano 
materials using simple techniques with enhanced physical and chemical properties that can have applications in diverse fields. Various analysis techniques have been focused on the application of graphene based composites in capacitors ${ }^{39}$ biosensors, ${ }^{40}$ solar cells ${ }^{41}$ and liquid crystalline displays. ${ }^{42}$ It has been thought that composite of $\mathrm{ZnO}$ with graphene is a perfect candidate to have the excellent photocatalytic performance due to the conjugated structure of graphene which help in the separation of charge in the photocatalysis process. $\mathrm{ZnO}$-graphene nanohybrids have been synthesized having regularly arranged $\mathrm{ZnO}$ nanorods on the graphene sheets possessing the high electrical property and excellent optical transmittance ${ }^{43} \mathrm{Lv}$ and co-workers have proposed $\mathrm{ZnO}-\mathrm{RGO}$ hybrid composites by using a microwave synthesis system, resulting in improved degradation of methylene blue dye. ${ }^{44}$ Zheng et al. have employed chemical vapour deposition technique to synthesize the $\mathrm{ZnO}$-graphene composite with exceptional field emission properties. ${ }^{45} \mathrm{ZnO}$-graphene thin films have the good capactive properties which are prepared by ultrasonic spray pyrolysis. ${ }^{46}$ However, the conditions that are used in all these processes are complex and can be carried out at high temperature only. The solution based processes are proved better as compared to the physical methods as they are cost effective for the fabrication of $\mathrm{ZnO}$ nanoparticles and its graphene based composites. ${ }^{20,47}$ Here in this study, a simple one step synthetic approach is explored for the synthesis of $\mathrm{ZnO}-\mathrm{NG}$ nano composites with the varying amounts of NG using ethylene glycol as a solvent. The ethylene glycol inhibits the aggregation of reduced nitrogen doped graphene sheets. In the further study, the photocatalytic activity of the $\mathrm{ZnO}-\mathrm{NG}$ for degradation of organic dye methylene blue was investigated and the obtained results were compared with naked $\mathrm{ZnO}$ nano particles. The effect of concentration of NG on the photocatalytic property of $\mathrm{ZnO}-\mathrm{NG}$ composites for degradation of methylene blue dye was investigated in detail.

\section{Experimental}

\section{1. Synthesis of Graphene Oxide (GO)}

Graphene oxide (GO) was synthesized from $99.99 \%$ pure natural graphite powder flakes, by modified Hummer's method. ${ }^{48}$ In this method, 3 g graphite powder flakes were added into $40 \mathrm{~mL}$ mixture of concentrated $\mathrm{H}_{2} \mathrm{SO}_{4}$ and $\mathrm{H}_{3} \mathrm{PO}_{4}$ (9:1) maintained at $0{ }^{\circ} \mathrm{C}$. To this mixture, $18 \mathrm{~g} \mathrm{KMnO}_{4}$ was added in small installments under vigorous stirring. The reaction mixture was stirred for $2 \mathrm{~h}$ below $10^{\circ} \mathrm{C}$ and then for another $1 \mathrm{~h}$ at $35^{\circ} \mathrm{C}$. After that the mixture was diluted with $100 \mathrm{~mL}$ of deionised water (DI) and stirred for $1 \mathrm{~h}$ in an ice bath to prevent overheating of reaction mixture. Then the residual $\mathrm{KMnO}_{4}$ present in the reaction mixture was reduced by adding $20 \mathrm{~mL}$ of $30 \% \mathrm{H}_{2} \mathrm{O}_{2}$. The brilliant yellow colored solution was obtained. The reaction mixture was washed with $5 \% \mathrm{HCl}$ aqueous solution to remove the metal ions followed by washing with deionised water to counteract the acidic nature of the solution until its $\mathrm{pH}$ value reaches 6 . The reaction mixture was centrifuged and obtained product was further purified by sonicating its dispersion in deionised water for $1 \mathrm{~h}$. Finally, the product was centrifuged and dried at $60^{\circ} \mathrm{C}$ for $24 \mathrm{~h}$.

\section{2. Synthesis of Nitrogen Doped Graphene (NG)}

Nitrogen doped graphene (NG) was synthesized by the pyrolysis of prepared graphene oxide (GO). $0.5 \mathrm{~g}$ GO and $0.6 \mathrm{~g}$ urea were dissolved in $30 \mathrm{~mL}$ ethanol and sonicated for $30 \mathrm{~min}$ to form the homogenous solution. Then the solution was heated at $60{ }^{\circ} \mathrm{C}$ to evaporate the solvent. The as obtained black mixture was grounded finely and heated at $350{ }^{\circ} \mathrm{C}$ in the muffle furnace at a heating rate of $5^{\circ} \mathrm{C} / \mathrm{min}$ for $12 \mathrm{~h}$. The obtained black powder was washed with ethanol and dried in oven at $60^{\circ} \mathrm{C}$ for $24 \mathrm{~h}$.

\section{3. Synthesis of Zinc Oxide/Nitrogen Doped Graphene Composites (ZnO-NG)}

$\mathrm{ZnO}-\mathrm{NG}$ composites were prepared via hydrothermal method by varying the content of NG as 10, 20, 30, 40 and $50 \mathrm{mg}$. Briefly, purified NG with different weight contents as mentioned were dispersed in $15 \mathrm{~mL}$ of ethylene glycol (EG) by ultrasonication treatment for $2 \mathrm{~h}$, labelled as solution A. Two separate solutions of zinc acetate $\left[\mathrm{Zn}\left(\mathrm{CH}_{3} \mathrm{COO}\right)_{2}\right]$ and sodium hydroxide $(\mathrm{NaOH})$ were prepared by dissolving $20 \mathrm{mg} \mathrm{Zn}\left(\mathrm{CH}_{3} \mathrm{COO}\right)_{2}$ and $10 \mathrm{mg}$ $\mathrm{NaOH}$ in $10 \mathrm{~mL}$ of EG, labelled as solution $\mathrm{B}$ and $\mathrm{C}$ respectively. Solution B and C are added to solution A and stirred for $1 \mathrm{~h}$ to obtain a homogenous suspension. The suspension was transferred to a $50 \mathrm{~mL}$ Teflon-lined stainless steel autoclave and maintained at $160^{\circ} \mathrm{C}$ for $24 \mathrm{~h}$ for the deposition of $\mathrm{ZnO}$ simultaneously. Finally, the resultant composite was centrifuged and washed with DI water followed by ethanol and dried at $70^{\circ} \mathrm{C}$ for $24 \mathrm{~h}$. Pure $\mathrm{ZnO}$ was also prepared by the same method under similar conditions. The as-prepared $\mathrm{ZnO}-\mathrm{NG}$ composites with 20, 30, 40, $50 \mathrm{mg}$ of NG were labelled as ZNG-1, ZNG-2, ZNG-3 and ZNG-4 respectively.

\section{4. Spectroscopic and Microscopic Measurements}

The phase and size of the as prepared samples were determined from powder X-ray diffraction (PXRD) using D8 X-ray diffractometer (Bruker) at a scanning rate of $12^{\circ} \mathrm{min}^{-1}$ in the $2 \theta$ range from $10^{\circ}$ to $80^{\circ}$, with $\mathrm{Cu} \mathrm{Ka}$ radiation $(\lambda=0.15405 \mathrm{~nm})$. Scanning electron microscopy (SEM) micrographs of the samples were recorded on FEI Nova Nano SEM 450. High Resolution Transmission Electron Microscopy (HRTEM) was recorded on Tecnai G2 20 
S-TWIN Transmission Electron Microscope with a field emission gun operating at $200 \mathrm{kV}$. The samples for TEM measurements were prepared by evaporating a drop of the colloid onto a carbon coated copper grid. The infrared spectra were recorded on Shimadzu Fourier Transform Infrared Spectrometer (FT-IR) over the range of wave number $4000-400 \mathrm{~cm}^{-1}$ and the standard $\mathrm{KBr}$ pellet technique was employed. All the measurements were performed at room temperature.

\section{5. Photocatalytic Measurements}

The catalytic activity of the as synthesized sample was performed by degradation of organic dye methylene Blue (MB) under the irradiation of visible light. For the Photo irradiation $500 \mathrm{~W}$ xenon lamp was used fitted with UV cut-off filters (JB450) in order to completely remove any radiation below $420 \mathrm{~nm}$ ensuring the exposure to only visible light. The whole procedure was performed at $25{ }^{\circ} \mathrm{C}$. A $100 \mathrm{~mL}$ of $\mathrm{MB}$ dye solution was prepared $(20$ $\mathrm{mg} / \mathrm{L}$ concentration) and $0.025 \mathrm{~g}$ of photocatalyst was mixed with dye solution. The resulting mixture was stirred for $1 \mathrm{~h}$ before illumination in order to establish the adsorption and desorption equilibrium between $\mathrm{MB}$ and catalyst surface. At the same time instant of time $5 \mathrm{~mL}$ of dye-catalyst mixture was taken out and concentration of the residual dye was determined with the help of UV-vis spectroscopy by measuring the absorption at $664 \mathrm{~nm}$. The absorbance of dye in presence of different catalysts (ZNG1, ZNG-2, ZNG-3 and ZNG-4) at $664 \mathrm{~nm}$ was monitored after fixed intervals of time. The absorbance of dye in presence of pure $\mathrm{ZnO}$ at same time intervals was also recorded for reference.

\section{Results and Discussion}

\section{1. PXRD Measurements}

The structural characterization of the nanoparticles has been carried out by Powder X-ray diffraction technique using $\mathrm{CuKa}$ radiation. The PXRD spectrum of GO, NG, ZnO, ZNG-1, ZNG-2, ZNG-3 and ZNG-4 composite materials are shown in the Figure. 1 and Figure. 2. Figure. $1 \mathrm{a}, \mathrm{b}$ show the differences of phase composition between GO and NG. The doping of nitrogen in GO can be shown easily by PXRD spectrum. The X-ray diffraction pattern of GO (Figure. 1a) shows one characteristic peak $\left(2 \theta^{\circ}\right)$ at $10.3^{\circ}$. The PXRD pattern of NG shown in Figure. $1 \mathrm{~b}$ has three characteristic peaks $\left(2 \theta^{\circ}\right)$ at $26.3^{\circ}(002), 31.92^{\circ}$ $(002)$ and $42.63^{\circ}(004)$. The results obtained for NG are in well agreement with literature (JCPDS Card No. 75$1621)^{44}$. The characteristic absorption peak of GO at $10.3^{\circ}$ was not found in PXRD spectrum of the NG which shows nitrogen doping of graphene oxide framework. The PXRD patterns of $\mathrm{ZnO}, \mathrm{ZnO} / \mathrm{NG}$ composites (Figure 2) there are following main peaks at $2 \theta=31.7^{\circ}, 34.4^{\circ}, 36.2^{\circ}$, $47.5^{\circ}, 56.6^{\circ}, 62.9^{\circ}, 66.3^{\circ}, 67.9^{\circ}, 69.2^{\circ}, 77.0^{\circ}$ which corresponds to the (1 $\left.\begin{array}{lll}1 & 0\end{array}\right),\left(\begin{array}{lll}0 & 0 & 2\end{array}\right),\left(\begin{array}{lll}1 & 0 & 1\end{array}\right),\left(\begin{array}{lll}1 & 0 & 2\end{array}\right),\left(\begin{array}{lll}1 & 1 & 0\end{array}\right),\left(\begin{array}{ll}1 & 0\end{array}\right.$ 3), (2 $\left.\begin{array}{lll}2 & 0\end{array}\right),\left(\begin{array}{lll}1 & 1 & 2\end{array}\right),\left(\begin{array}{lll}2 & 0 & 1\end{array}\right)$ and (2 $\left.0 \begin{array}{ll}2\end{array}\right)$ planes of $\mathrm{ZnO}$ nano crystals respectively (JCPDS No. $36-1451) .{ }^{49}$ The reduction of nitrogen doped graphene takes place by the alcohol in the hydrothermal conditions so no peak corresponding to (002) plane is visible in the composite. It can also be attributed to efficient exfoliation of the NG sheets in the resultant composites so this reason can be given disappearance of the NG patterns in the XRD spectrum of $\mathrm{ZnO} / \mathrm{NG}$ composites.

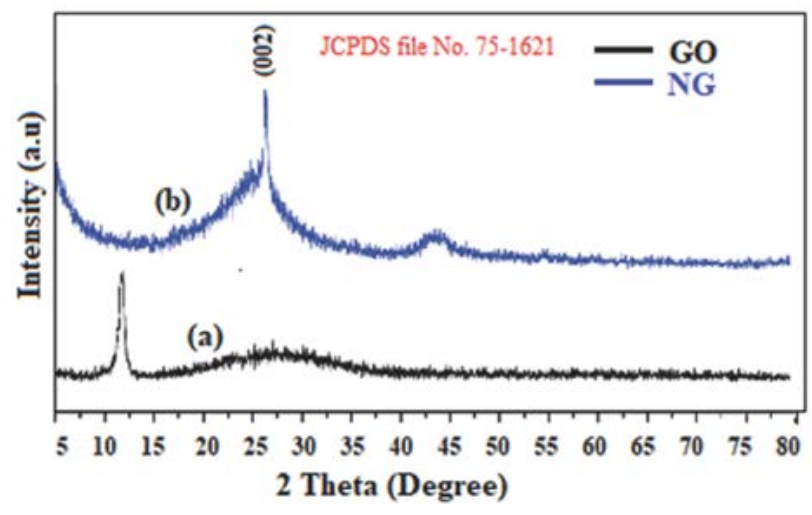

Figure 1. PXRD patterns of (a) GO (b) NG

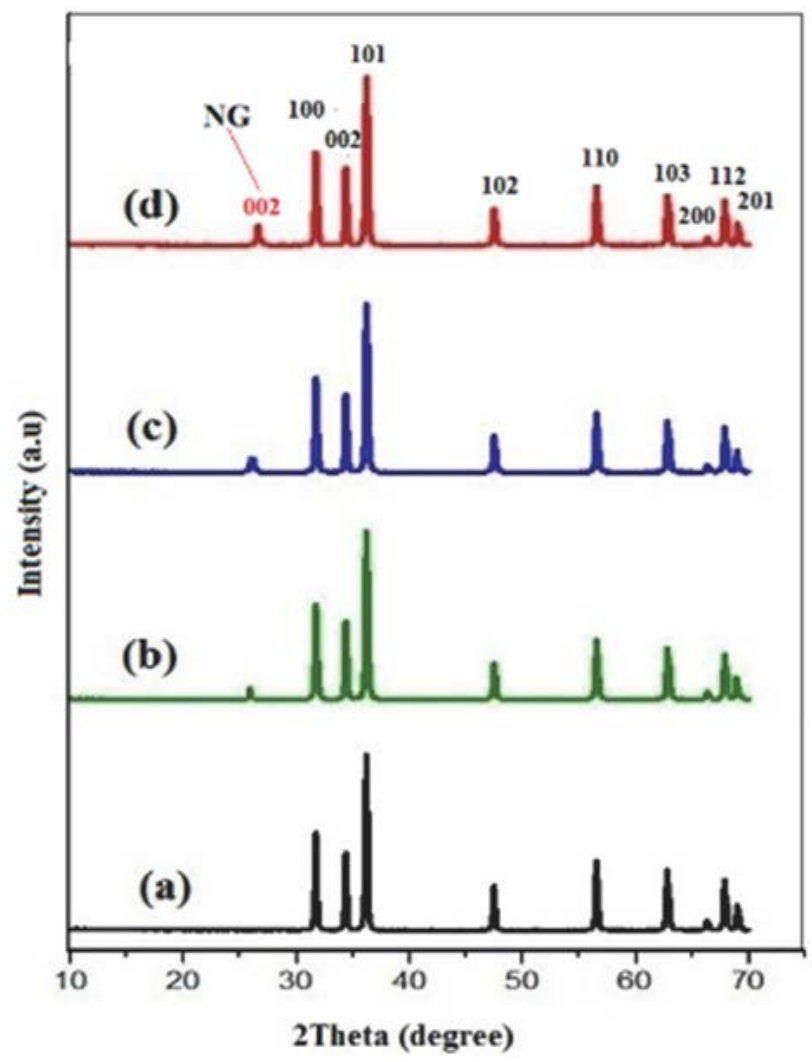

Figure 2. PXRD patterns of (a) ZnO (b) ZG-1 (c) ZG-2 (c) ZG-3 (d) ZG-4 
The average crystallite size of these nanoparticles was calculated according to the Scherrer's equation.

$$
\beta=\frac{K \lambda}{L \operatorname{Cos} \theta}
$$

where, $L(n m)$ is the crystallite size, $\lambda(n m)$ is the wavelength of the $\mathrm{Cu} \mathrm{Ka}$ radiant, $\lambda=0.15405 \mathrm{~nm}, \beta\left(^{\circ}\right)$ is the full-width at half-maximum (FWHM) of the diffraction peak, $\theta$ is the diffraction angle and $\mathrm{K}$ is the Scherrer constant equal to 0.89 . All the major peaks were used to calculate the average crystallite size of the $\mathrm{ZnO}$ and $\mathrm{ZnO} / \mathrm{NG}$ nanoparticles. The estimated average crystallite sizes of nanoparticles are in the range of 80-120 nm.

\section{2. FT-IR Characterization}

FTIR spectra of GO, NG was shown in Figure. 3a, b. There are many $\mathrm{O}$-containing groups that exist on $\mathrm{GO}$ sheets, such as hydroxyl, epoxy, and carboxyl groups. Majority of the O-containing groups will disappear after reduction. FTIR bands at 1050, 1220, 1405 and $1730 \mathrm{~cm}^{-1}$ were observed for GO. These bands correspond to $\mathrm{C}-\mathrm{O}$ stretching, $\mathrm{C}-\mathrm{O}-\mathrm{C}$ stretching, $\mathrm{O}-\mathrm{H}$ deformation vibra-

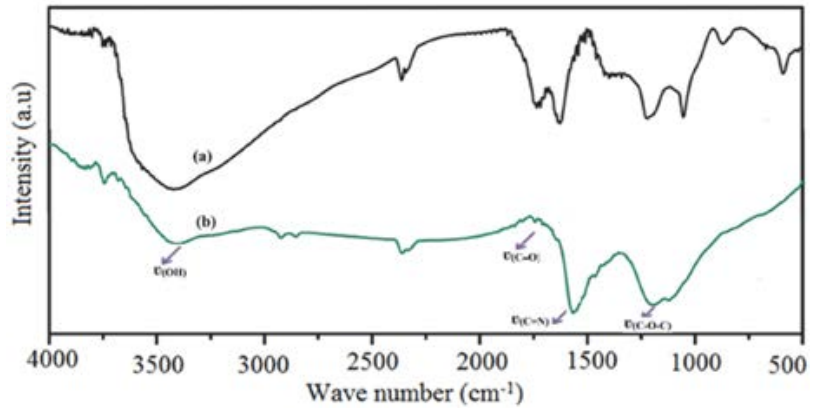

Figure 3. FTIR spectra of (a) GO (b) NG

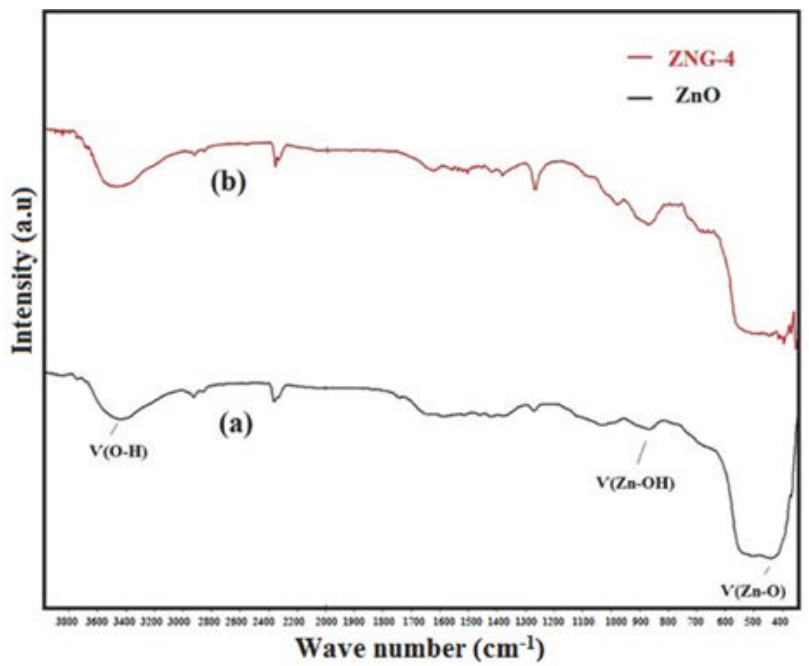

Figure 4. FTIR of (c) $\mathrm{ZnO}$ (d) ZNG-4. tion and $\mathrm{C}=\mathrm{O}$ carbonyl stretching. ${ }^{50}$ FTIR bands at 1400 $\mathrm{cm}^{-1}$ due to $\mathrm{C}=\mathrm{C}$ stretching is observed in $\mathrm{NG}$ and the $v_{(\mathrm{C}=\mathrm{O})}$ band at $1730 \mathrm{~cm}^{-1}$ completely disappeared due to reduction. The bands located at 1180 and $1565 \mathrm{~cm}^{-1}$ in Figure. $3 \mathrm{~b}$ are assigned to the $v_{(\mathrm{C}-\mathrm{N})}$ and $v_{(\mathrm{C}=\mathrm{C})}$ respectively. The FTIR spectra suggest nitrogen doping of GO. Figure. $4 \mathrm{a}, \mathrm{b}$ shows the FT-IR bands of $\mathrm{ZnO}$ and $\mathrm{ZnO}-\mathrm{NG}$. The absorption band at $450 \mathrm{~cm}^{-1}$ is attributed to the stretching modes of $\mathrm{Zn}-\mathrm{O}$. Furthermore, it is observed that almost all the characteristic bands of oxygen containing functional groups $(\mathrm{C}=\mathrm{O}, \mathrm{O}-\mathrm{H}, \mathrm{C}-\mathrm{OH}$ and $\mathrm{C}-\mathrm{O}-\mathrm{C}$ ) disappeared in the FT-IR spectrum of $\mathrm{ZnO}-\mathrm{NG}$ suggesting the nitrogen doping of graphene oxide and uniform anchoring of $\mathrm{ZnO}$ onto the surface of $\mathrm{NG}^{51}$. The results above show the heteroatom $\mathrm{N}$ was entered in the graphene structure and the $\mathrm{ZnO}-\mathrm{NG}$ composites were prepared favourably.

\section{3. Raman Analysis}

The Raman spectrum of the as synthesized NG and ZNG-4 are shown in Figure 5a and 5b respectively. In the Figure. 5 two noticeable peaks at 1340 and $1600 \mathrm{~cm}^{-1}$ indicating the $\mathrm{D}$ and $\mathrm{G}$ band respectively. The ratio of the intensity of $\mathrm{D}$ and $\mathrm{G}$ band indicates disorder, as revealed by the $\mathrm{sp}^{2} / \mathrm{sp}^{3}$ carbon proportion. The $\mathrm{G}$ band indicates in (plane bond(stretching motion of pairs of $\mathrm{sp}^{2} \mathrm{C}$ atoms. The $\mathrm{D}$ band ("disordered" band) is the breathing mode of the $\mathrm{sp}^{2}$ rings of the graphene layer which corresponds to a range of defects: bond angle disorder, bond length disor-

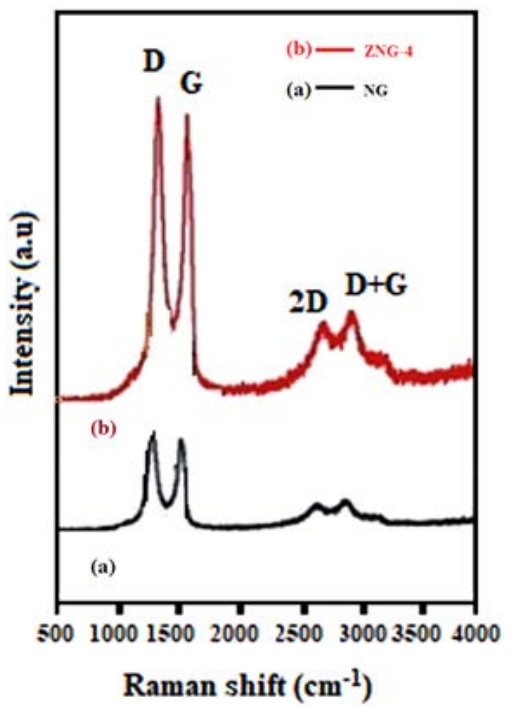

Figure 5. Raman spectrum of (a) NG (b) ZNG-4.

der and hybridization caused by heteroatom (nitrogen/ oxygen) doping and structure defects. Therefore, the relatively increased intensity of the D band for NG indicates that the content of disordered carbon increases, particularly by nitrogen doping. 


\section{4. SEM and TEM Analysis}

Figure. $6 \mathrm{a}$ and $7 \mathrm{a}$ depicts scanning electron microscopy and transmission electron microscopy images of as prepared GO respectively. The scanning electron microscopy, suggested layered structure and crumpled surface morphology of as synthesized graphene oxide. Furthermore, by analysing the TEM image (Figure. 7a) it was revealed that GO has stacked layer by layer structure and has morphology like the wrinkled paper. The morphological changes can be attributed to excessive carboxylic, phenolic

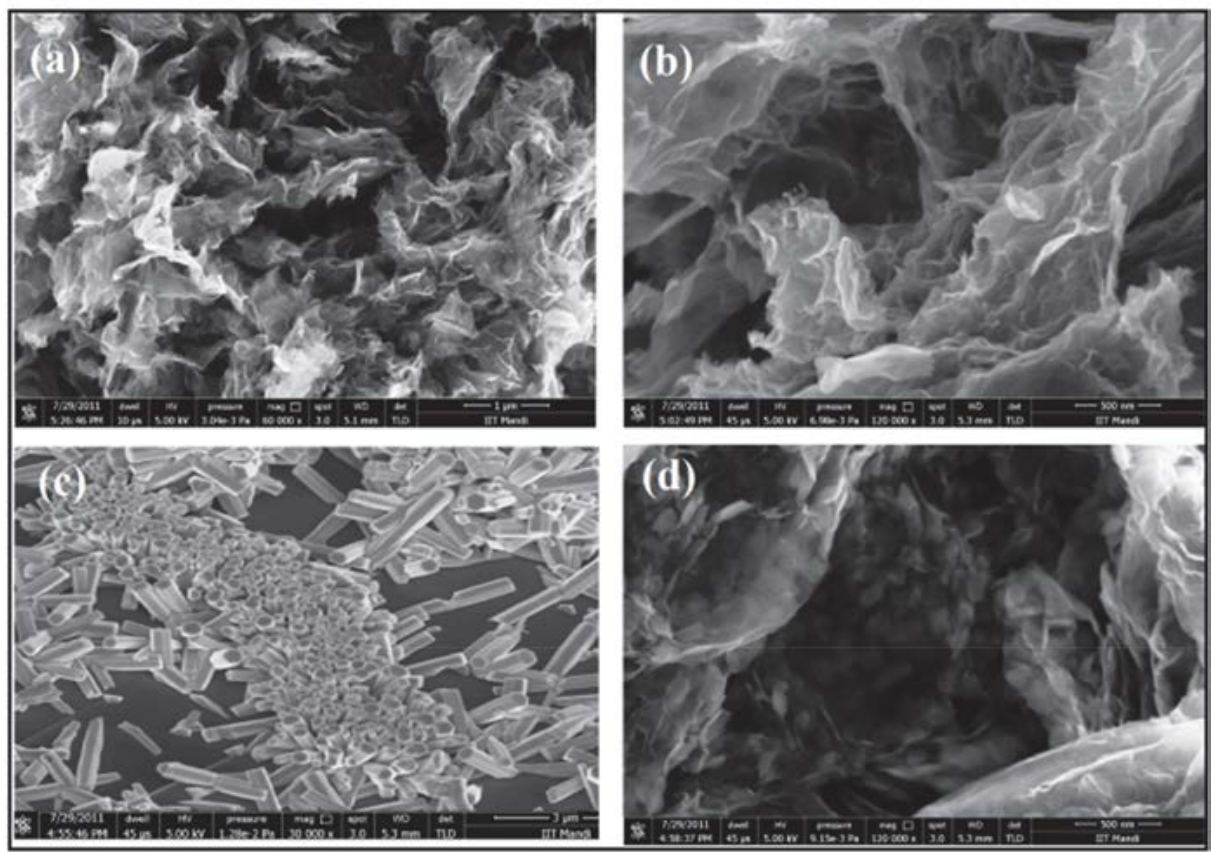

Figure 6. SEM micrographs of (a) GO (b) NG (c) ZnO (d) ZNG-4.

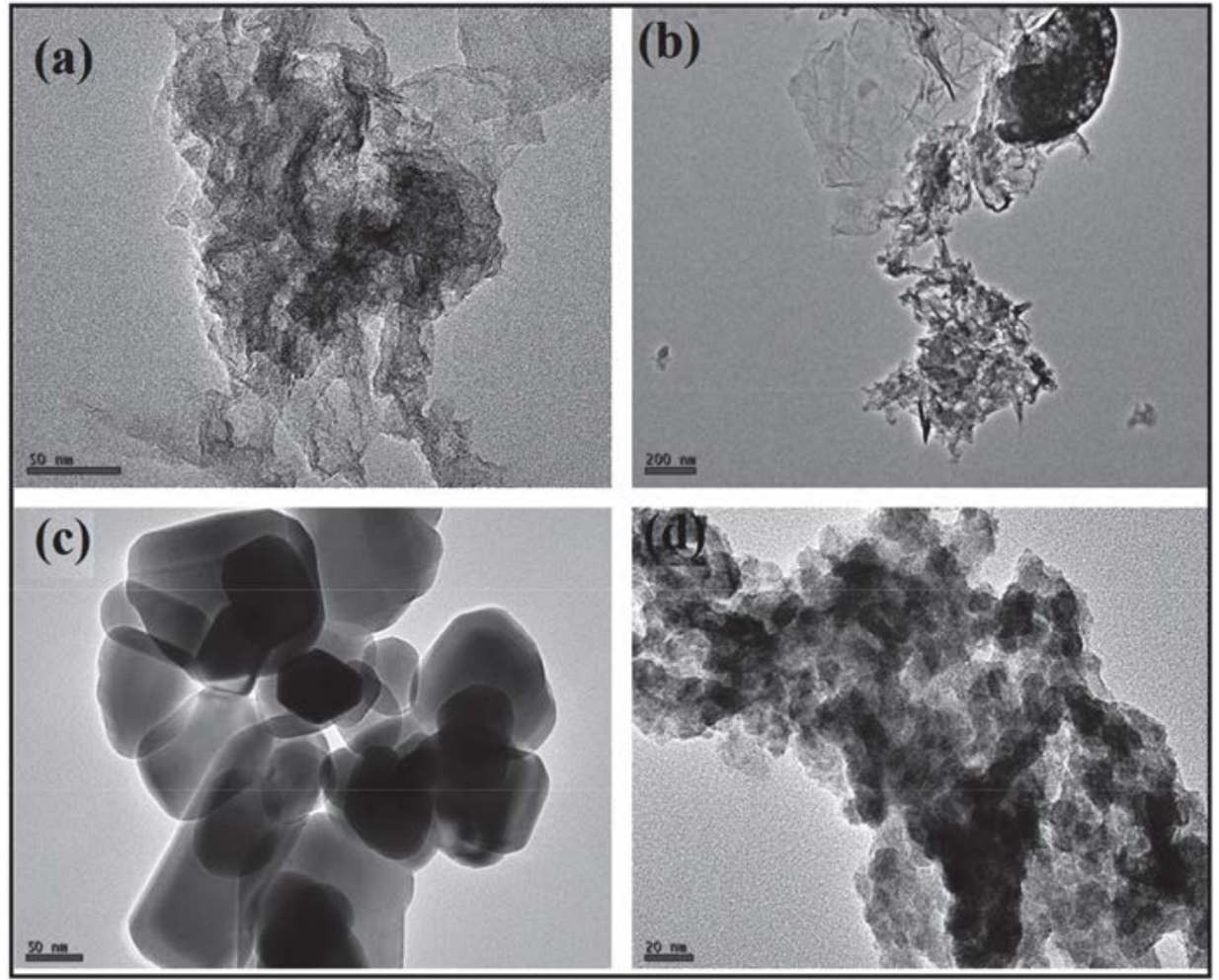

Figure 7. TEM micrographs of (a) GO (b) NG (c) ZnO (d) ZNG-4 
and epoxy functional groups on the basal plane of GO. The curled and overlapped nanosheets of GO can be clearly observed. Figure. 6b and Figure. $7 \mathrm{~b}$ represent nitrogen-doped graphene nano-sheets which shows a highly wrinkled topology, by virtue of stable thermodynamic bending. ${ }^{45,46}$ SEM image of the $\mathrm{ZnO}$ is shown in Figure. $6 \mathrm{c}$ which suggested rectangular rods like morphology of the prepared sample. Figure. 6d is SEM image of ZNG-4 sample which clearly shows a uniform distribution of $\mathrm{ZnO}$ on the surface of NG. Furthermore the SEM results are supported by TEM analysis of $\mathrm{ZnO}$ and ZNG-4 as shown in Figure. $7 \mathrm{c}$ and $\mathrm{d}$ respectively. The morphological features of prepared nanostructures are in close agreement with reported literature. ${ }^{52}$ The particle size data obtained from TEM data by using Image $J$ software are in very close agreement to the size calculated from the Debye-Scherrer method.

\section{5. Photocatalytic Measurements}

The photocatalytic decomposition of organic dye $\mathrm{MB}$ under the visible light was helpful to show the photocatalytic performance at $25{ }^{\circ} \mathrm{C}$ of the prepared $\mathrm{ZnO}$, ZNG-1, ZNG-2, ZNG-3, ZNG-4. The photocatalytic degradation profile of $\mathrm{MB}$ solution (concentration of $\mathrm{MB}, \mathrm{C}$ $=0.075 \mathrm{M}$ and path length, $l=1 \mathrm{~cm}$ ) in the presence of different composites was shown in the Figure. 7. It has been found that the MB dye (blank solution) was not decomposed even after 90 min exposure to the visible light. The ZnO-NG composites shows better photocatalytic activity than $\mathrm{ZnO}$. The decomposition rate of $\mathrm{MB}$ for $\mathrm{ZnO}$ was found $58 \%$ but on the introduction of nitrogen doped graphene the decomposition rate was increased to $76 \%, 88 \%$, and $93 \%$ corresponding to ZNG-1, ZNG-2, ZNG-3 respectively. And for the ZNG-4 it reaches a maximum value of $99.5 \%$. These results shows that the

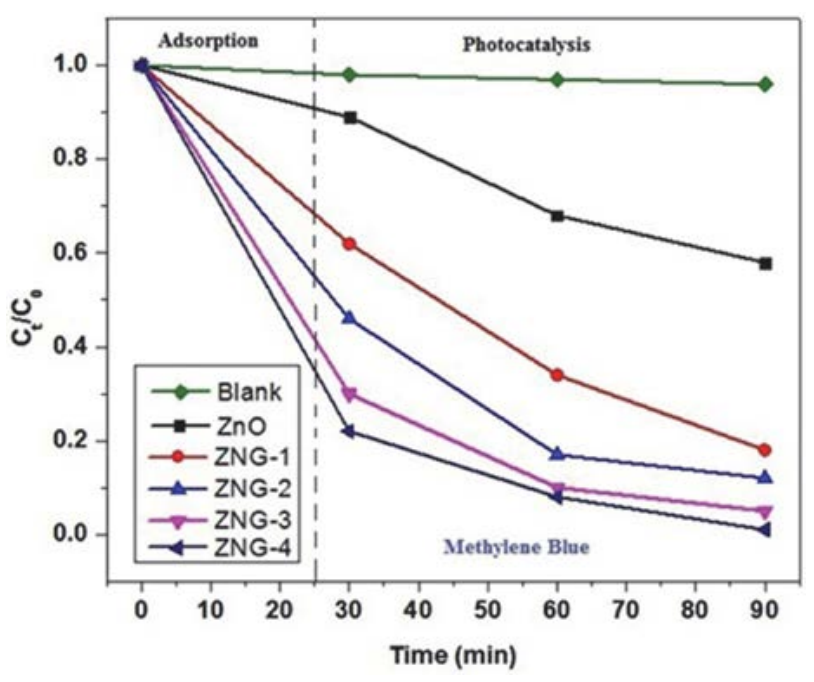

Figure 8. The kinetics of photodegradation of MB. presence of nitrogen doped graphene has vital importance in the photocatalytic process and can be shown by the plot of $\mathrm{C}_{\mathrm{t}} / \mathrm{C}_{0}$ versus time $(\mathrm{min})$. The degradation process for the various photocatalysts was shown in the Figure. 7.

\section{6 Mechanism of Photocatalysis}

A possible mechanism of photocatalytic degradation of $\mathrm{MB}$ over the $\mathrm{ZnO}-\mathrm{NG}$ nanocomposite has been suggested based on the photocatalytic studies as shown in Figure. 9. Upon the visible light irradiation, the electrons are excited in the valence band (VB) to the conduction band (CB) of $\mathrm{ZnO}$ nanoparticles, thus generating holes $\left(\mathrm{h}^{+}\right)$in the VB. The electron produced transferred to the $\mathrm{CB}$ of carbon layers of nitrogen doped graphene and which discharge the photogenerated electrons which get reacted with the oxygen $\left(\mathrm{O}_{2}\right)$ to produce super oxide anion radicals $\left(\mathrm{O}_{2}\right)$. The huge separation rate of $\mathrm{h}^{+}$easily reacts with water molecules $\left(\mathrm{H}_{2} \mathrm{O}\right)$ to generate the hydroxyl radicals $(\mathrm{OH})$. The presence of the above radicals results into the degradation of the adsorbed $\mathrm{MB}$ dye onto the surface of ZnO-NG nanocomposite. The effective electron transfer process with nitrogen doped graphene layers as electron receiver and transporter leads to the enhanced photocatalytic activity of the $\mathrm{ZnO}-\mathrm{NG}$ nanocomposite under the visible light irradiation. Nitrogen doped graphene prevents electron-hole pairs recombination onto the surface of $\mathrm{ZnO}$ nanoparticles (NPs). ${ }^{53-55}$ So, the enhancement of photocatalytic activity was given to the synergistic effect between $\mathrm{ZnO}$ NPs and nitrogen doped graphene layers. Furthermore the role of $\mathrm{NG}$ in in photodegradation of $\mathrm{MB}$ might be double fold;

1. Nitrogen doped graphene (NG) increases adsorption of tested dyes (MB) on the surface of $\mathrm{ZNG}$ photocatalyst(s), as result of $\pi-\pi$ conjugation between aromatic region of the dye and nanosheets of nitrogen doped graphene..$^{56,57}$

2. It is also helpful in suppression of recombination of charges in $\mathrm{ZnO}$, as $\mathrm{NG}$ acts as photoelectron ac-

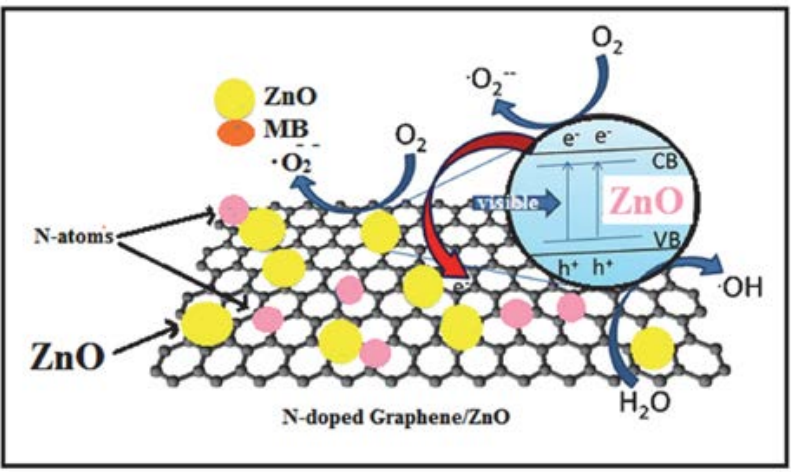

Figure 9. Proposed mechanism of photodegradation process MB dye. 
ceptor and there by facilitate a higher photocatalytic activity of prepared nanocomposites. ${ }^{58,59}$

\section{7. Recyclability and Reusability of As-Synthesised Photocatalyst (ZNG-4)}

For a greener-ecofriendly approach and practical applications, reuse and recyclability of a phocatalyst is prime requirement. This makes the process cost effective and free of waste. The reusability and recycling efficiency of as-synthesized photocatalyst (ZNG-4) was tested against photodegradation of methylene blue (MB). It can be noted that photocatalyst (ZNG-4) shows appreciable activity even after the five cycles. The results are shown in Figure. 10.

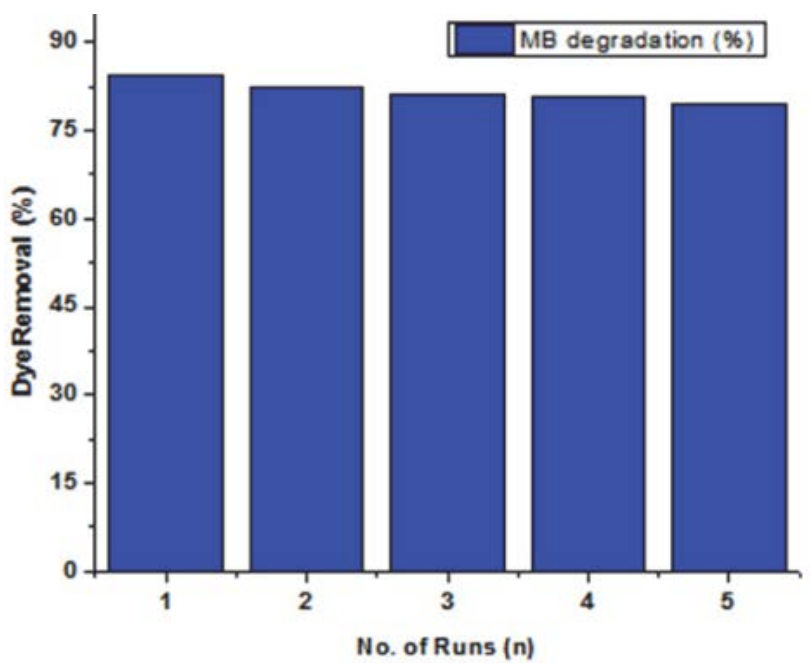

Figure 10. Recyclability of ZNG-4 in Photodegradation of MB dye (upto 5 cycles).

\section{Conclusions}

In conclusion, we have reported the structural, photocatalytic properties of $\mathrm{ZnO}, \mathrm{ZnO}-\mathrm{NG}$ nanocomposites prepared by hydrothermal method. PXRD patterns are in well agreement with the $\mathrm{ZnO}$ and nitrogen doped graphene structure. SEM and TEM images reveal the morphological and topological features of nitrogen doped graphene, $\mathrm{ZnO}$, ZnO-NG respectively. The crystallite size of synthesized nanocomposites as calculated from PXRD and TEM analysis was found to be in the range of $80-120 \mathrm{~nm}$. The photocatalytic results show that photodegradation of $\mathrm{MB}$ in presence of nanocomposites was enhanced compared to bare $\mathrm{ZnO}$.

\section{Acknowledgement}

We would like to acknowledge SAIF, Panjab University for their technical support. We thank Indian Institute of Technology Mandi for powder X-ray diffraction study. One of the authors (R. S.) is thankful to UGC-Delhi for the financial support.

\section{References}

1. Z. Liu, W. Xu, J. Fang, X Xu, S. Wu, X. Zhu, Z. Chen, Appl. Surf. Sci. 2012, 259, 441-447.

DOI:10.1016/j.apsusc.2012.07.063

2. W. Xu, G. Zhou, J. Fang, Z. Liu, Y. Chen, C. Cen. Int. J. Photoenergy. 2013, 2013, Aug 7. DOI:10.1155/2013/234806

3. W. Xu, Z. Liu, J. Fang, G. Zhou, X. Hong, S. Wu, X. Zhu, Y. Chen, C. Cen Int. J. Photoenergy. 2013, 2013, jul 29. DOI:10.1155/2013/394079

4. Y. Liao, W. Que, Z. Tang, W. Wang, W. Zhao, J Alloys Compd. 2011, 509, 1054-1059. DOI:10.1016/j.jallcom.2010.09.175

5. N. R. Khalid, E. Ahmed, Z. Hong, M. Ahmad, Appl. Surf. Sci. 2012, 263, 254-259. DOI:10.1016/j.apsusc.2012.09.039

6. J. Wang, D. N. Tafen, J. P. Lewis, Z. L. Hong, A. Manivannan, M. J. Zhi, M. Li, N. Q. Wu, J. Am. Chem. Soc. 2009, 131, 12290-12297. DOI:10.1021/ja903781h

7. C. Wang, J. Yan, X. Wu, Y. Song, G. Cai, H. Xu, J. Zhu, H. Li, Appl. Surf. Sci. 2013, 273,159-166.

DOI:10.1016/j.apsusc.2013.02.004

8. M. Li, Z. L. Hong, Y. N. Fang, F. Q. Huang, Mater. Res. Bull. 2008, 43, 2179-2186.

DOI:10.1016/j.materresbull.2007.08.030

9. M. Li, P. S.Tang, Z. L. Hong, M. Q. Wang, Colloids Surf., A. 2008, 318, 285-290. DOI:10.1016/j.colsurfa.2008.01.001

10. R. M. Asmussen, M. Tian, A. Chen, Environ. Sci. Technol. 2009, 43, 5100-5105. DOI:10.1021/es900582m

11. T. Hirakawa, P. V. Kamat, J. Am. Chem. Soc. 2005, 127, 3928 3934. DOI:10.1021/ja042925a

12. P. V. Kamat, M. Flumiani, A. Dawson Colloids and surf. A. 2002, 202, 269-279.

DOI:10.1016/S0927-7757(01)01071-8

13. K. Vinodgopal, P. V. Kamat, Environ. Sci. Technol.1995, 29(3), 841-485. DOI:10.1021/es00003a037

14. V. Subramanian, E. E. Wolf, P. V. J. Kamat, J. Am. Chem. Soc. 2004, 126, 4943-4950. DOI:10.1021/ja0315199

15. S. H. Elder, F. M. Cot, Y. Su, S. M. Heald, A. M. Tyryshkin, M. K. Bowman, Y. Gao, A. G. Joly, M. L. Balmer, A. C. Kolwaite, K. A. Magrini, D. M. Blake, J. Am. Chem. Soc. 2000, 122, 5138-5146. DOI:10.1021/ja992768t

16. T. Tatsuma, S. Saitoh, P. Ngaotrakanwiwat, Y. Ohko, A. Fujishima, Langmuir 2002, 18, 7777-7779.

DOI:10.1021/la026011i

17. J. Aguado, R. V. Grieken, M. J. Lopez-Munos, J. Marugan, Appl. Catal. 2006, 312, 202-212.

DOI:10.1016/j.apcata.2006.07.003

18. B. Li, H. Cao, J. Mater. Chem. 2011, 21, 3346-3349. DOI:10.1039/C0JM03253K

19. J. Matos, A. Garcia, T. Cordero, J. M. Chovelon, C. Ferronato, Catal. Lett. 2009, 130, 568-574.

DOI:10.1007/s10562-009-9989-8 
20. K. Woan, G. Pyrigiotakis, W. Sigmund, Adv. Mater. 2009, 21, 2233-2239. DOI:10.1002/adma.200802738

21. M. Li, S. F. Zhou, Y. W. Zhang, G. Q. Chen, Z. L. Hong, Appl. Surf. Sci. 2008, 254, 3762-3766.

DOI:10.1016/j.apsusc.2007.11.047

22. Y. Yang, Liu, Appl. Surf. Sci. 2011, 257, 8950-8954.https://doi. org/10.1016/j.apsusc.2011.05.070

23. H. Zhang, X. Lv, Y. Li, Y. Wang, J. Li, ACS Nano, 2010, 4, 380-386. DOI:10.1021/nn901221k

24. X. Zhou, T. Shi, H. Zhou, Appl. Surf. Sci. 2012, 258, 62046211. DOI:10.1016/j.apsusc.2012.02.131

25. N. R. Khalid, Z. L. Hong, E. Ahmed, Y. W. Zhang, H. Chan, M. Ahmad, Appl. Surf. Sci. 2012, 258, 5827-5834. DOI:10.1016/j.apsusc.2012.02.110

26. A. A. Casaos, I. Tacchini, A. Unzue, M. T. Martinez, Appl. Surf. Sci. 2013, 270, 675-684.

DOI:10.1016/j.apsusc.2013.01.120

27. N. R. Khalid, E. Ahmed, Z. L. Hong, Y. W. Zhang, M. Ahmad, Curr. Appl. Phys. 2012, 12, 1485-1492.

DOI:10.1016/j.cap.2012.04.019

28. K. S. Novoselov, A. K. Geim, S. V. Morozov, D. Jiang, M. I. Katsnelson, I. V. Grigorieva, S. V. Dubonos, A. A. Firsov, Nature, 2005, 438, 197-200. DOI:10.1038/nature04233

29. A. K. Geim, K. S. Novoselov, Nat. Mater. 2007, 6(3), 183-191. DOI: $10.1038 / \mathrm{nmat} 1849$

30. A. C. Neto, F. Guinea, N. M. Peres, K. S. Novoselov, A. K. Geim, Rev. Mod. Phys. 2009, 81(1), 109-155.

DOI:10.1103/RevModPhys.81.109

31. Y. P. Zhang, C. Z. Luo, W. P. Li; C. X. Pan, Nanoscale, 2013, 5, 2616-2619. DOI:10.1039/C3NR34141K

32. Y. P. Zhang, D. L. Li, X. J. Tan, B. Zhang, X. F. Ruan, H. J. Liu, C. X. Pan, L. Liao, T. Zhai, Y. Bando, S. S. Chen, W. W. Cai, R. S. Ruo, Carbon, 2013, 54, 143-148.

DOI:10.1016/j.carbon.2012.11.012

33. D. F. Sun, X. B. Yan, J. W. Lang, Q. J. Xue, J. Power Sources, 2013, 222 52-58. DOI:10.1016/j.jpowsour.2012.08.059

34. Y. Huang, J. J. Liang, Y. S. Chen, Small, 2012, 8, 1805-1834. DOI:10.1002/smll.201102635

35. X. S. Du, C. F. Zhou, H. Y. Liu, Y. W. Mai, G. X. Wang, J. Power Sources, 2013, 241, 460-466.

DOI:10.1016/j.jpowsour.2013.04.138

36. W. Fan, Y. Y. Xia, W. W. Tjiu, P. K. Pallathadka, C. B. He, T. X. Liu, J. Power Sources 2013, 243, 973-981.

DOI:10.1016/j.jpowsour.2013.05.184

37. H. M. Jeong, J. W. Lee, W. H. Shin, Y. J. Choi, H. J. Shin, J. K. Kang, J. W. Choi, Nano Lett. 2011, 11, 2472-2477. DOI:10.1021/nl2009058

38. G. X. Luo, L. Z. Liu, J. F. Zhang, G. B. Li, B. L.Wang, J. J. Zhao, ACS Appl. Mater. Interfaces, 2013, 5, 11184-11193.

DOI:10.1021/am403427h

39. X. Chen, C. Fu, W. Yang, Analyst, 2009, 134, 2135-2140. DOI:10.1039/B910754A
40. N. L.Yang, J. Zhai, D. Wang, Y.S. Chen, L. Jiang, ACS Nano 2010, 4, 887-894. DOI:10.1021/nn901660v

41. P. Blake, P. D. Brimicombe, R. R. Nair, T. J. Booth, D. Jiang, F. Schedin, L. A. Ponomarenko, S. V. Morozov, H. F. Gleeson, E. W. Hill, A. K. Geim, K. S. Novoselov, Nano Lett. 2008, 8, 1704-1708. DOI:10.1021/nl080649i

42. X. Y. Zhang, H. P. Li, X. L. Cui, Y. Lin, J. Mater. Chem. 2010, 20, 2801-2806. DOI:10.1039/B917240H

43. J. M. Lee, Y. B. Pyun, J. Yi, J. W. Choung, W. I. Park, J. Phys. Chem. C 2009, 113, 19134-19138. DOI:10.1021/jp9078713

44. T. Lv, L. Pan, X. Liu, T. Lu, G. Zhu, Z. Sun, J Alloys Compd. 2011, 509, 10086. DOI:10.1016/j.jallcom.2011.08.045

45. W. T. Zheng, Y. M. Ho, H. W. Tian, M. Wen, J. L. Qi, Y. A. Li, J. Phys. Chem. C 2009, 113, 9164-9168.

DOI:10.1021/jp900881q

46. Y. Zhang, H. Li, L. Pan, T. Lu, Z. Sun, J. Electroanal. Chem. 2009, 634, 68-71. DOI:10.1016/j.jelechem.2009.07.010

47. B. Li, T. Liu, Y. Wang, Z. Wang, J. Colloid Interface Sci. 2012, 377, 114-121. DOI:10.1016/j.jcis.2012.03.060

48. W. S. Hummers, R. E. Offeman, J. Am. Chem.Soc. 1958, 80, 1339-1339.

49. M. Ahmad, E. Ahmed, Z. L. Honga, J. F. Xua, N. R. Khalida, A. Elhissi, W. Ahmed Appl. Surf. Sci. 2013, 274 273-281. DOI:10.1016/j.apsusc.2013.03.035

50. M. Acik, C. Mattevi, C. Gong, G. Lee, K. Cho, M. Chhowalla, ACS Nano 2010, 10, 5861-5868. DOI:10.1021/nn101844t

51. A. K. Mageed, AB DR, A. Salmiaton, S. Izhar, M. A. Razak, H. M. Yusoff, F. M. Yasin, S. Kamarudin International Journal of Applied Chemistry, 2016, 12(1), 104-8.

52. W. Zou, J. Zhu, Y. Sun, X. Wang, Mater. Chem. Phys. 2011, 125, 617-620. DOI:10.1016/j.matchemphys.2010.10.008

53. B. Li, T. Liu, Y. Wang, Z. Wang, J. Colloid Interface Sci. 2012, 377, 114-121. DOI:10.1016/j.jcis.2012.03.060

54. R. Atchudan, T.N.J.I. Edison, S. Perumal, M. Shanmigam, Y. R. Lee, J. Photochem. Photobiol. A, 2017, 337, 100-111. DOI:10.1016/j.jphotochem.2017.01.021

55. R. Cai, J. Wu, L. Sun, Y. Liu, T. Fang, S. Zhu, S. Li, Y. Wang, L. Guo, C. Zhao, A. Wei, Mater. Des. 2016, 90, 90839-844. http://10.1016/j.matdes.2015.11.020

56. P. Chen, T. Y. Xiao, H. H Li, J. J Yang, Z. Wang, H. B. Yao, S. H. Yu, ACS Nano, 2011 6, 712-719.

DOI: $10.1021 / \mathrm{nn} 204191 \mathrm{x}$

57. M. Kumar, R. Singh, H. Khajuria, H. N. Sheikh, J. Mater. Sci. Mater. Electron., 2017, 28, 9423-9434.

DOI:10.1007/s10854-017-6684-1

58. K. Gopalakrishnan, H. M. Joshi, P. Kumar, L. S. Panchakarla, C. N. R. Rao, Chem. Phys. Lett., 2011, 511, 304-308.

DOI:10.1016/j.cplett.2011 .06.033

59. R. Singh, M. Kumar, H. Khajuria, J. Ladol, H. N. Sheikh, Chemical Papers, 2018, 1-12.

DOI:10.1007/s11696-018-0385-y 


\section{Povzetek}

S preprostim enostopenjskim solvotermalnim sinteznim postopkom smo pripravili nano fotokatalizator na osnovi $\mathrm{ZnO}$ na grafenu, dopiranem $z$ dušikom (ZNG). V sinteznem postopku smo uporabili etilen glikol kot topilo, ki hkrati preprečuje agregacijo plasti grafena. Depozicijo nanodelcev ZnO na plasti grafena dopiranega $\mathrm{z}$ dušikom smo potrdili s presevno elektronsko mikroskopijo visoke ločljivosti (HR-TEM), vrstično elektronsko mikroskopijo (SEM), rentgensko praškovno difrakcijo (XRD) in infrardečo spektroskopijo (FTIR). UV-Vis spektroskopijo smo uporabili za preučevanje fotokatalitične aktivnosti, ki je višja v primerjavi s samimi nanodelci ZnO. Višjo fotokatalitično aktivnost lahko pripišemo sinergističnim učinkom povečane absorbcije barvila, povišane absorbcije vidne svetlobe in efektivne ločitve naboja. 